\title{
Not a Disease of the Past: A Case Series of Progressive Multifocal Leukoencephalopathy in the Established Antiretroviral Era
}

\author{
Nathan A. Summers, ${ }^{1,2}$ Colleen F. Kelley, ${ }^{1-3}$ Wendy Armstrong, ${ }^{1,2}$ \\ Vincent C. Marconi, ${ }^{1,2,4}$ and Minh Ly Nguyen ${ }^{1,2}$
}

\begin{abstract}
Progressive multifocal leukoencephalopathy (PML) and PML immune reconstitution inflammatory syndrome (PML-IRIS) can be devastating neurological processes associated with HIV, but limited knowledge of their characteristics in the established antiretroviral therapy (ART) era is available. We conducted a case series to evaluate the clinical course of PML and PML-IRIS at our urban safety-net hospital in Atlanta, GA. All HIV-positive individuals with a positive John Cunningham virus DNA polymerase chain reaction in the spinal fluid between May 1, 2013 to June 1, 2017 were identified from the electronic health records (EHRs) using the HIV Disease Registry. Demographics, symptom presentation, laboratory data, imaging results, treatment, and outcomes were abstracted from the EHR. PML and PML-IRIS were defined using the American Association of Neurology criteria. Of the 32 individuals identified, $6(19 \%)$ were felt to have asymptomatic positive results. Of the remainder, 15 (58\%) HIV-positive patients had PML and 11 (42\%) PML-IRIS (2 with an unmasking presentation and 9 with a paradoxical presentation). The most common presenting symptoms were motor weakness $(18,69 \%)$, cognitive deficits $(15,58 \%)$, and dysarthria $(11,42 \%)$. Corticosteroids were used in 12 patients and maraviroc in 3 patients. Outcomes were dismal with 7 (47\%) patients with PML and 9 (82\%) with PML-IRIS dying or being referred to hospice, with median survival times of 266 days in the PML group and 109 days in the PML-IRIS group. Despite widespread access to ART, patients with PML continue to have poor outcomes, particularly among those who develop PML-IRIS. More research is needed to understand the risks for and prevention of PML-IRIS.
\end{abstract}

Keywords: HIV, JCV, PML, IRIS, immune reconstitution inflammatory syndrome

\section{Introduction}

$\mathbf{P}$ ROGRESSIVE MULTIFOCAL leukoencephalopathy (PML) is a progressive neurological disorder characterized by focal demyelination of central nervous system (CNS) white matter. This results in a constellation of symptoms, including loss of coordination, gait disturbances, cognitive decline, visual impairment, and limb paresis. ${ }^{1}$ The causative agent of PML is the John Cunningham virus (JCV), a ubiquitous polyoma virus named after the patient from whom it was first isolated. ${ }^{2}$ Primary infection generally occurs in childhood and is asymptomatic, resulting in a chronic carrier state. Although PML is most commonly associated with advanced HIV, it is also occasionally seen in other immunocompromised states, including hematologic malignancies, recipients of solid organ transplants, and those receiving humanized monoclonal antibodies, such as natalizumab, efalizumab, and rituximab. ${ }^{1,3,4}$ Diagnosis of PML is based on clinical and radiological findings in the appropriate clinical setting. ${ }^{5}$ Unfortunately, the prognosis is very poor in the majority of cases. There is no specific therapy for PML, but with the advent of effective antiretroviral therapy (ART), 1-year survival after diagnosis has improved from $10 \%$ to $50 \%$ among persons living with HIV (PLWH). ${ }^{6}$

Immune reconstitution inflammatory syndrome (IRIS) is an exaggerated host immune response to a specific disease or

\footnotetext{
${ }^{1}$ Department of Medicine, Division of Infectious Diseases, Emory University School of Medicine, Atlanta, Georgia.

${ }^{2}$ Grady Health Systems, Atlanta, Georgia.

${ }^{3}$ Department of Epidemiology, Rollins School of Public Health, Emory University, Atlanta, Georgia

${ }^{4}$ Department of Global Health, Rollins School of Public Health, Emory University, Atlanta, Georgia.
} 
pathogen that follows immune system recovery, such as after initiation of ART. There are two manifestations of IRIS: paradoxical, a worsening of a previously diagnosed disease after starting ART, and unmasking the discovery of a previously undiagnosed disease after starting ART., ${ }^{3,5}$ IRIS is commonly associated with a low initial $\mathrm{CD} 4^{+}$cell count, a rapid decrease of the initial elevated HIV viral load, and typically presents 4 to 8 weeks after initiation of ART. PMLIRIS can be devastating and is associated with a rapid progression of the disease either clinically, radiologically, or both. Although there is some evidence supporting the use of steroids in these cases, this evidence is limited by loose definitions of PML-IRIS requiring only progression of disease rather than evidence of inflammation, conflicting outcome data, and variable duration of corticosteroids used. ${ }^{3,7,8}$ Another potential therapy for PML and PML-IRIS is maraviroc, a chemokine receptor 5 (CCR5) inhibitor, used in the treatment of HIV, which has recently been studied in the treatment and prevention of PML-IRIS, as the immune cell trafficking to the CNS in PML-IRIS appears to occur in a CCR5-dependent mechanism. ${ }^{9,10}$ As a result, maraviroc is currently being used anecdotally for the treatment of PMLIRIS in both the multiple sclerosis and HIV populations, with mixed results. ${ }^{11-13}$ Because the initial studies describing immune cell trafficking in PML-IRIS were performed in HIV-negative patients, there is some concern that these results may not apply to PLWH and PML-IRIS. ${ }^{14}$ Therefore, guidelines for the management of PML-IRIS do not make definitive recommendations regarding the use of maraviroc, citing a lack of quality evidence to support its general use. ${ }^{3}$

Although PML and PML-IRIS can be devastating neurological processes associated with HIV, there is limited data available on their characteristics in the established ART era. We performed a retrospective review of all PLWH who had a positive cerebrospinal fluid (CSF) JCV polymerase chain reaction (PCR) from May 1, 2013 through June 1, 2017 to assess the clinical presentation and outcomes of PML and PML-IRIS in the modern ART era.

\section{Materials and Methods}

\section{Case definitions}

All cases were initially identified from the registry by a positive JCV PCR isolated from the CSF. All CSF samples were sent to Quest Diagnostics (Chantilly, VA) for qualitative JCV PCR testing. Testing was performed using the inhouse real-time PCR targeting a highly conserved sequence of large $\mathrm{T}$ antigen, with a limit of quantitation of $500 \mathrm{cop}-$ ies $/ \mathrm{mL}$ and limit of detection of 375 copies $/ \mathrm{mL}$. PML cases were defined using the 2013 American Academy of Neurology's consensus statement. ${ }^{15}$ Definite PML was defined as meeting both clinical features (cognitive/behavioral abnormalities, motor weaknesses, gait abnormality/incoordination, sensory loss, speech/language disorder, visual defects, and seizures) and radiographic findings on magnetic resonance imaging (MRI) (hyperintense lesions on T2-weighted images that are hypointense on T1-weighted images in subcortical or periventricular white matter). Probable cases, where either only clinical features or only radiographic findings were compatible with the diagnosis of PML, were included in the analysis if the physicians caring for the patient documented in the electronic health records (EHRs) that PML was the most likely cause for the patient's symptoms. Possible cases, where neither the clinical features nor radiographic findings were compatible with the diagnosis of PML, were considered to have asymptomatic positive CSF JCV PCR results.

Cases of PML-IRIS were identified using previously validated definitions. ${ }^{5}$ Patients had to meet criteria for PML in addition to four additional criteria: (1) administration of ART within the previous 2 years, (2) subacute onset of neurological deficits that either appeared (unmasking PML-IRIS) or was exacerbated after initiation of ART (paradoxical PMLIRIS), (3) decrease in plasma HIV RNA viral $\operatorname{load}_{\text {of }} \geq 1 \log _{10}$ copies/mL with or without an increase in CD4 T cell count from baseline at the onset or worsening of symptoms, and (4) evidence of an inflammatory reaction in the brain demonstrated by MRI (contrast enhancement, edema, and/or mass effect) to distinguish PML-IRIS from usual progression of previously acquired PML. Cases could be considered to be PML-IRIS cases if the baseline HIV RNA viral load or viral load at diagnosis was not available but satisfied the other criteria.

\section{Data abstraction}

Using the previous described definitions, this study included all cases of positive CSF JCV PCR in PLWH between May 1, 2013 and June 1, 2017 within the Emory University Center for AIDS Research (CFAR) registry, which collects data from the EHR of PLWH who are cared for in the Grady Health System. The Grady Health System cares for a primarily underserved population in the metropolitan Atlanta area in Georgia and includes Grady Memorial Hospital as well as the Infectious Diseases Program outpatient HIV specialty clinic. There were 7,873 unique individuals registered in the Emory University CFAR registry during this study period. The registry was accessed in August 2017 and PLWH who tested positive for JCV by PCR in the CSF were included for manual chart review to confirm eligibility for inclusion in the case series. Patient demographics, symptom presentation, laboratory data, imaging results, treatment, and outcomes were abstracted from the EHR.

\section{Data analysis}

All statistical tests were performed using SAS software, version 9.4 (SAS Institute, Cary, NC). A descriptive analysis of baseline characteristics was performed, which were then compared between the two groups (PML vs. PML-IRIS) using two-sample $t$-tests (continuous variables) and chisquare tests (categorical variables) to identify unique characteristics between the two entities. Cochran-MantelHaenszel $(\mathrm{CMH})$ odds ratios (OR) were calculated to determine factors associated with both the development of PML-IRIS as well as the development of a composite outcome of discharge to hospice or withdrawal of care. Logit estimators of the CMH OR were performed using a correction of 0.5 in every cell of those tables that contained a zero when necessary. Comparison of survival time for PLWH with PML or PML-IRIS was performed using Kaplan-Meier curves. Survival time was calculated from the date of the positive CSF JCV PCR to the last documented encounter with the patient in the EHR. A $p$ value $<.05$ was considered statistically significant. 


\section{Results}

There were 32 patients with a positive qualitative CSF JCV PCR initially identified between May 1, 2013 and June 1, 2017 out of the 7,873 unique PLWH in the registry. Six patients did not meet diagnostic criteria for PML or PML-IRIS and were classified as asymptomatic positive CSF JCV PCR. This yielded 26 total cases, of which 15 met criteria for PML and 11 met criteria for PML-IRIS (two with an unmasking presentation and nine with a paradoxical presentation) (Fig. 1), giving an estimated rate of 8.09 cases per 10,000 person years.

Baseline patient information is presented in Table 1. The majority of patients in all three groups (asymptomatic CSF JCV, PML, and PML-IRIS) were African American men with a mean age between 43.58 to 46.79 years and a mean CD4 count between 58 to 65 cells $/ \mu \mathrm{L}$ at the time of CSF sampling. Age, gender, ethnicity, CD4 count, HIV viral load, symptom duration, and duration of HIV did not significantly vary between patients with PML and PML-IRIS. The most common finding on MRI for patients with PML was white matter changes (13 of $15,86.67 \%$ ), whereas patients with PML-IRIS were noted to have more inflammatory changes, including contrast enhancement (5 of 11, 45.45\%) and mass effect ( 3 of $11,27.27 \%$ ). The most common treatment for PML-IRIS was corticosteroids (9 of 11, 81.82\%), followed by the addition of maraviroc to the ART regimen ( 3 of 11 , $27.27 \%$ ). The three patients (3 of 15, 20\%) with PML who were given corticosteroids had progression of disease with worsening neurological decline and clinical concern for IRIS despite not meeting diagnostic criteria for PML-IRIS. Outcomes were poor in both groups, with 7 of 15 (46.67\%) progressing to hospice or death in the PML group and 9 of 11 $(81.82 \%)$ progressing to hospice or death in the PML-IRIS group with median survival times of 266 days in the PML group and 109 days in the PML-IRIS group (Table 3). This difference in outcomes approached statistical significance $(p=.05)$.

As seen in Table 2, baseline patient demographics were not significantly associated with the diagnosis of PML-IRIS. The presenting neurological symptoms, however, varied somewhat between patients with PML and PML-IRIS. Patients with PML-IRIS more often presented with motor symptoms
$(\mathrm{OR}=8.75,95 \%$ confidence interval $(\mathrm{CI}): 0.88-86.60)$, dysarthria $(\mathrm{OR}=10.67,95 \% \mathrm{CI}: 1.71-66.72)$, and ataxia $(\mathrm{OR}=7.00,95 \% \mathrm{CI}: 1.20-40.83)$.

As seen in Table 3, there were no factors that were significantly associated with progression to demise, hospice, or withdrawal of care. Although not statistically significant, individuals who presented with $\mathrm{CD} 4$ count $\leq 50$ cells $/ \mu \mathrm{L}$ $(\mathrm{OR}=3.60$, 95\% CI: 0.71-18.25), dysarthria $(\mathrm{OR}=2.63$, 95\% CI: 0.53-13.07), and visual changes ( $O R=2.18,95 \%$ CI: 0.17-27.56) tended to have higher odds of poor outcomes, as did those who were ultimately diagnosed with PML-IRIS ( $\mathrm{OR}=2.63$, 95\% CI: 0.53-13.07). Additionally, individuals who received treatment with either corticosteroids with or without the addition of maraviroc were also observed to have nonstatistically significant higher odds of poor outcomes (OR $=5.00,95 \%$ CI: 0.79-31.63).

Table 4 describes basic information on the individuals diagnosed with an asymptomatic positive CSF JCV PCR, along with other recent opportunistic infections (OI), outcomes, and alternative diagnoses. OI were common, with 3 of $6(50 \%)$ asymptomatic cases having other ongoing OI, including disseminated Mycobacterium avium complex (2, $33.33 \%)$, CNS toxoplasmosis $(1,16.67 \%)$, and Cryptococcal meningitis $(1,16.67 \%)$. One patient had recently recovered from Cryptococcal meningitis within the previous year.

A more detailed description of the 11 patients with PMLIRIS is presented in Table 5. ART regimens, CD4 count trends (when available), and corticosteroid dose and duration are shown. Dates are provided to outline a relative timeline for events. The majority of patients with PML-IRIS had poor ART adherence documented before their diagnosis of PML (9/12, 75\%). Corticosteroids, when used, were started after imaging indicated PML-IRIS. Of the three patients treated with maraviroc, one patient was started before the development of PML-IRIS, explicitly for the prevention of PML-IRIS, whereas the other two were started after IRIS had developed, explicitly for the treatment of PML-IRIS. Maraviroc was not used in any of the patients with PML.

Kaplan-Meier curves comparing survival time between patients with PML and PML-IRIS are shown in Figure 2. Patients with PML-IRIS were found to have shorter survival times than patients with PML, which trended toward significance (Log-Rank $p=.05$ ).

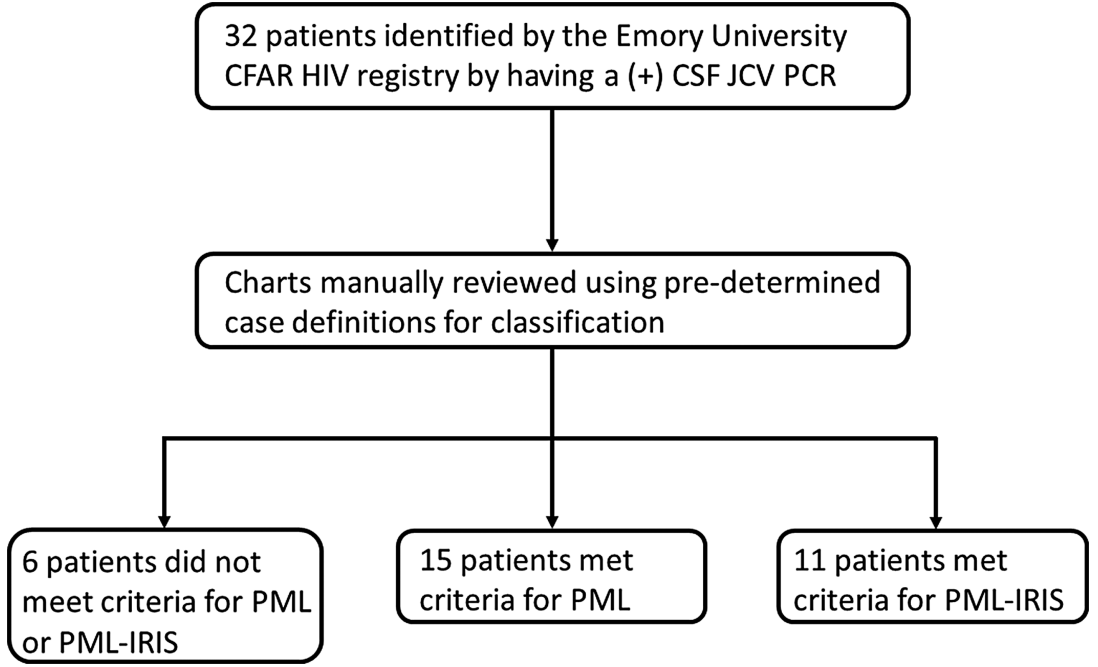

FIG. 1. Study design. CFAR, Center for AIDS Research; CSF, cerebrospinal fluid; IRIS, immune reconstitution inflammatory syndrome; JCV, John Cunningham virus; PCR, polymerase chain reaction; PML, progressive multifocal leukoencephalopathy. 
Table 1. Characteristics of Patients with Positive Cerebrospinal Fluid John Cunningham Virus Polymerase Chain Reaction $(N=32)$

\begin{tabular}{|c|c|c|c|}
\hline Demographic & Asymptomatic CSF JCV $(\mathrm{n}=6)$ & $P M L(\mathrm{n}=15)$ & $P M L-I R I S(\mathrm{n}=11)$ \\
\hline Age & $46.79(16.04)$ & $45.32(11.78)$ & $43.58(9.92)$ \\
\hline Male, $n(\%)$ & $3(50)$ & $11(73.33)$ & $9(81.82)$ \\
\hline \multicolumn{4}{|l|}{ Ethnicity, $n(\%)$} \\
\hline Black & $6(100)$ & $14(93.33)$ & $9(81.82)$ \\
\hline Asian & $0(0)$ & $1(6.67)$ & $2(18.18)$ \\
\hline \multicolumn{4}{|l|}{ ART regimen at diagnosis, $n(\%)$} \\
\hline INSTI & $2(33.33)$ & $5(33.33)$ & $6(54.55)$ \\
\hline PI & $2(33.33)$ & $12(80)$ & $5(45.45)$ \\
\hline CD4 (cells $/ \mu \mathrm{L})$ & $58(48.80)$ & $65(66.87)$ & $64(51.45)$ \\
\hline CD4 $(\%)$ & $7.50(6.16)$ & $6.73(5.79)$ & $5.54(4.03)$ \\
\hline HIV viral load $\left(\log _{10}\right.$ copies $\left./ \mathrm{mL}\right)$ & $4.03(2.01)$ & $4.46(1.29)$ & $3.58(2.17)$ \\
\hline Symptom duration (days) & $22.60(38.63)$ & $37.14(36.87)$ & $42.10(31.89)$ \\
\hline HIV duration (days) & $919(1222.71)$ & $3105(316)$ & $2132(2388)$ \\
\hline ART duration before diagnosis (days) ${ }^{b}$ & - & $96.75(308.30)$ & $27.80(119.40)$ \\
\hline Survival time (days) & $420(477)$ & $266(370)$ & $109(118)$ \\
\hline \multicolumn{4}{|l|}{ Presenting neurological symptoms, $n(\%)$} \\
\hline Motor weakness & $0(0)$ & $8(53.33)$ & $10(90.91)$ \\
\hline Cognitive dysfunction & $3(50)$ & $11(73.33)$ & $4(36.36)$ \\
\hline Dysarthria & $0(0)$ & $3(20.00)$ & $8(72.73)$ \\
\hline Ataxia & $0(0)$ & $3(20.00)$ & $7(63.64)$ \\
\hline Cranial nerve palsy & $0(0)$ & $1(6.67)$ & $4(36.36)$ \\
\hline Seizures & $2(33.33)$ & $4(26.67)$ & $1(9.09)$ \\
\hline Visual changes & $1(16.67)$ & $2(13.33)$ & $1(9.09)$ \\
\hline \multicolumn{4}{|l|}{ Radiological findings on MRI, $n(\%)$} \\
\hline White matter involvement & $0(0)$ & $13(86.67)$ & $11(100)$ \\
\hline Contrast enhancement & $1(16.67)$ & $0(0)$ & $5(45.45)$ \\
\hline Mass effect & $1(16.67)$ & $1(6.67)$ & $3(27.27)$ \\
\hline Corticosteroid use, $n(\%)$ & $0(0)$ & $3(20.00)$ & $9(81.82)$ \\
\hline Addition of maraviroc to ART regimen, $n(\%)$ & $0(0)$ & $0(0)$ & $3(27.27)$ \\
\hline Death or hospice, $n(\%)$ & $4(66.67)$ & 7 (46.67) & $9(81.82)$ \\
\hline
\end{tabular}

\footnotetext{
All values reported are frequency (\%) or mean (standard deviation).

${ }^{a}$ Asymptomatic CSF JCV were individuals with positive results but not meeting diagnostic criteria for PML or PML-IRIS.

${ }^{\mathrm{b}}$ Number of patients with JCV Infection on ART before diagnosis = 1, PML on ART before diagnosis = 12, number of patients with PMLIRIS on ART before diagnosis $=10$.

ART, antiretroviral therapy; CSF, cerebrospinal fluid; INSTI, integrase strand transfer inhibitor; IRIS, immune reconstitution inflammatory syndrome; JCV, John Cunningham virus; MRI, magnetic resonance imaging; PI, protease inhibitor; PML, progressive multifocal leukoencephalopathy.
}

Table 2. Factors Associated with the Diagnosis of Progressive Multifocal LEUKOENCEPHALOPATHY-RELATED IMMUNE RECONSTITUTION INFLAMMATORY SyNDROME $(N=26)$

\begin{tabular}{lcccc}
\hline Factor & $P M L, \mathrm{n}(\%)$ & $P M L-I R I S, \mathrm{n}(\%)$ & OR $(95 \% C I)$ & $\mathrm{p}$ \\
\hline Male gender & $11 / 15(73.33)$ & $9 / 11(81.82)$ & $1.64(0.24-11.08)$ & 0.62 \\
Age $>45$ years & $8 / 15(53.33)$ & $6 / 11(54.55)$ & $1.05(0.22$ to 5.00$)$ & 0.95 \\
CD4 $\leq 50$ cells $\mu \mathrm{L}$ & $9 / 15(60.00)$ & $5 / 11(45.45)$ & $0.56(0.12-2.68)$ & 0.47 \\
HIV viral load $>4.87 \log _{10}$ copies/mL $\mathrm{mL}^{\mathrm{a}}$ & $9 / 15(60.00)$ & $3 / 10(30.00)$ & $0.29(0.05-1.57)$ & 0.15 \\
ART regimen at the time of diagnosis & & & & \\
$\quad$ INSTI & $5 / 15(33.33)$ & $6 / 11(54.55)$ & $2.40(0.48-11.89)$ & 0.29 \\
$\quad$ PI & $12 / 15(80.00)$ & $5 / 11(45.45)$ & $0.21(0.04-1.18)$ & 0.07 \\
Presenting neurological symptoms & & & & \\
$\quad$ Motor weakness & $8 / 15(53.33)$ & $10 / 11(90.91)$ & $8.75(0.88-86.60)$ & 0.04 \\
Cognitive dysfunction & $11 / 15(73.33)$ & $4 / 11(36.36)$ & $0.21(0.04-1.11)$ & 0.06 \\
$\quad$ Dysarthria & $3 / 15(11.54)$ & $8 / 11(72.73)$ & $10.67(1.71-66.72)$ & 0.01 \\
$\quad$ Ataxia & $3 / 15(20.00)$ & $7 / 11(63.64)$ & $7.00(1.20-40.83)$ & 0.03 \\
$\quad$ Cranial nerve palsy & $1 / 15(6.67)$ & $4 / 11(36.36)$ & $8.00(0.75-85.73)$ & 0.06 \\
$\quad$ Seizures & $4 / 15(26.67)$ & $1 / 11(9.09)$ & $0.28(0.03-2.89)$ & 0.27 \\
$\quad$ Visual changes & $2 / 15(13.33)$ & $1 / 11(9.09)$ & $0.65(0.05-8.23)$ & 0.74 \\
\hline
\end{tabular}

${ }^{\mathrm{a}} 4.87 \log _{10}$ copies/mL, median viral load.

$\mathrm{CI}$, confidence interval; OR, odds ratio. 
Table 3. Factors Affecting Progression to Hospice or Withdrawal of Care $(N=26)$

\begin{tabular}{|c|c|c|c|}
\hline Factor & Frequency of outcome ${ }^{\mathrm{a}}$ when present, n (\%) & OR $(95 \% C I)$ & $\mathrm{p}$ \\
\hline \multicolumn{4}{|c|}{ Presenting neurological symptoms } \\
\hline Motor weakness & $9 / 18(50)$ & $1.00(0.19-5.29)$ & 1.00 \\
\hline Cognitive dysfunction & $7 / 15(46.67)$ & $0.73(0.15-3.47)$ & 0.70 \\
\hline Dysarthria & $7 / 11(63.64)$ & $2.63(0.53-13.07)$ & 0.24 \\
\hline Ataxia & $6 / 10(60)$ & $1.93(0.39-9.60)$ & 0.43 \\
\hline Cranial nerve palsy & $3 / 5(60)$ & $1.65(0.23-11.99)$ & 0.63 \\
\hline Seizures & $3 / 5(60)$ & $1.65(0.23-11.99)$ & 0.63 \\
\hline Visual changes & 2/3 (66.67) & $2.18(0.17-27.56)$ & 0.55 \\
\hline \multicolumn{4}{|l|}{ Radiological findings } \\
\hline White matter involvement & $13 / 24(54.17)$ & $5.87(0.25-135.15)$ & $0.15^{\mathrm{b}}$ \\
\hline Contrast enhancement & $3 / 5(60)$ & $1.65(0.23-11.99)$ & 0.63 \\
\hline Mass effect & $2 / 4(50)$ & $1.00(0.12-8.42)$ & 1.00 \\
\hline Edema & $2 / 3(66.67)$ & $2.18(0.17-27.56)$ & 0.55 \\
\hline PML-IRIS & $7 / 11(63.64)$ & $2.63(0.53-13.07)$ & 0.24 \\
\hline $\mathrm{CD} 4 \leq 50$ cells $/ \mu \mathrm{L}$ & $9 / 14(64.29)$ & $3.60(0.71-18.25)$ & 0.12 \\
\hline Treatment $^{\mathrm{c}}$ & $10 / 12(83.33)$ & $5.00(0.79-31.63)$ & 0.08 \\
\hline
\end{tabular}

${ }^{\mathrm{a} C}$ Composite outcome: discharge to hospice or withdrawal of care.

${ }^{\mathrm{b}}$ Logit estimators use a correction of 0.5 in every cell for those tables that contain a zero.

${ }^{\mathrm{c}}$ Treatment was with corticosteroids in 12 individuals, 3 of whom were also started on maraviroc.

\section{Discussion}

We described a case series of PLWH with a positive CSF JCV PCR in the late ART era over a 4-year period. One interesting observation was the high rates of PML-IRIS identified in our case series. While rates of PML-IRIS have varied in other recent works from $4 \%$ to $31 \%$, we found that 11 of 26 cases $(42 \%)$ included in this study were diagnosed with PML-IRIS. ${ }^{16-18}$ Although it can be difficult to differentiate the natural progression of PML from PML-IRIS, we believe our findings are accurate because of the strict criteria used to define PML-IRIS in an attempt to avoid overdiagnosis. ${ }^{5}$ One factor that may have contributed to the high incidence of PML-IRIS was the high proportion of all patients who were treated with integrase strand transfer inhib- itors (INSTIs; 11 of $26,42 \%$ ), which have been previously shown to be associated with higher incidence of IRIS, felt to be related to the rapid decline in plasma HIV viral load. ${ }^{19}$ INSTIs have been observed to have excellent CNS penetrance, ${ }^{20}$ which has been shown to be associated with improved rates of HIV viral suppression within the CSF. ${ }^{21}$ Unfortunately, viral suppression in the CSF has not correlated well with incident AIDS-defining neurological conditions, ${ }^{22}$ so the adjustment of an ART regimen based on concern for PML or PML-IRIS is not supported at this time. Additionally, it is not clear if a rapid decline in the CSF HIV viral load affects the development of IRIS in the CNS more than the decline in plasma HIV viral load does. ${ }^{23}$ That said, the fact that we limited our case series to only include the modern ART era, which includes more

Table 4. Patient Characteristics for Individuals with an Asymptomatic Positive Cerebrospinal Fluid John Cunningham Virus Polymerase Chain Reaction $(N=6)$

\begin{tabular}{|c|c|c|c|c|c|c|c|c|}
\hline Patient & Gender & $\begin{array}{l}\text { Date CSF } \\
\quad J C V\end{array}$ & $\begin{array}{l}\text { Other } O I \\
\text { no. } 1\end{array}$ & $\begin{array}{c}\text { Date } O I \\
\text { no. } 1\end{array}$ & $\begin{array}{l}\text { Other } O I \\
\text { no. } 2\end{array}$ & $\begin{array}{c}\text { Date } O I \\
\text { no. } 2\end{array}$ & $\begin{array}{l}\text { Outcome } \\
\text { (date) }\end{array}$ & $\begin{array}{c}\text { Alternative } \\
\text { diagnosis }\end{array}$ \\
\hline 1 & $\mathrm{~F}$ & $\begin{array}{l}\text { October } \\
\quad 7,2013\end{array}$ & - & - & - & 一 & $\begin{array}{l}\text { Hospice } \\
\quad \text { (October } \\
27,2013)\end{array}$ & HIV dementia \\
\hline 2 & $\mathrm{~F}$ & $\begin{array}{l}\text { October } \\
28,2013\end{array}$ & DMAC & $\begin{array}{r}\text { September } \\
21,2013\end{array}$ & - & - & $\begin{array}{l}\text { Hospice } \\
\text { (April } \\
\text { 1, 2014) }\end{array}$ & Unknown \\
\hline 3 & M & $\begin{array}{l}\text { February } \\
5,2014\end{array}$ & - & - & - & - & Good & Psychosis \\
\hline 4 & $\mathrm{~F}$ & $\begin{array}{l}\text { February } \\
\qquad 1,2015^{\mathrm{a}}\end{array}$ & DMAC & $\begin{array}{l}\text { February } \\
1,2015\end{array}$ & $\begin{array}{l}\text { CNS } \\
\quad \text { Toxoplasmosis }\end{array}$ & $\begin{array}{l}\text { February } \\
1,2015\end{array}$ & $\begin{array}{l}\text { Hospice } \\
\quad \text { (April } \\
\quad \text { 3, 2015) }\end{array}$ & $\begin{array}{l}\text { CNS } \\
\text { Toxoplasmosis }\end{array}$ \\
\hline 5 & M & $\begin{array}{l}\text { July } \\
\qquad 15,2015\end{array}$ & $\begin{array}{c}\text { Cryptococcal } \\
\text { meningitis }\end{array}$ & $\begin{array}{l}\text { March } \\
\quad 4,2014\end{array}$ & - & - & Good & Unknown \\
\hline 6 & M & $\begin{array}{r}\text { November } \\
10,2015\end{array}$ & $\begin{array}{c}\text { Cryptococcal } \\
\text { meningitis }\end{array}$ & $\begin{array}{c}\text { November } \\
\quad 7,2015\end{array}$ & - & - & $\begin{array}{l}\text { Hospice } \\
\text { (February } \\
20,2017)\end{array}$ & $\begin{array}{c}\text { Cryptococcal } \\
\text { meningitis }\end{array}$ \\
\hline
\end{tabular}

${ }^{a}$ Repeat CSF JCV was positive on March 212015.

CNS, central nervous system; DMAC, disseminated Mycobacterium avium complex; F, female; M, male; OI, opportunistic infection. 


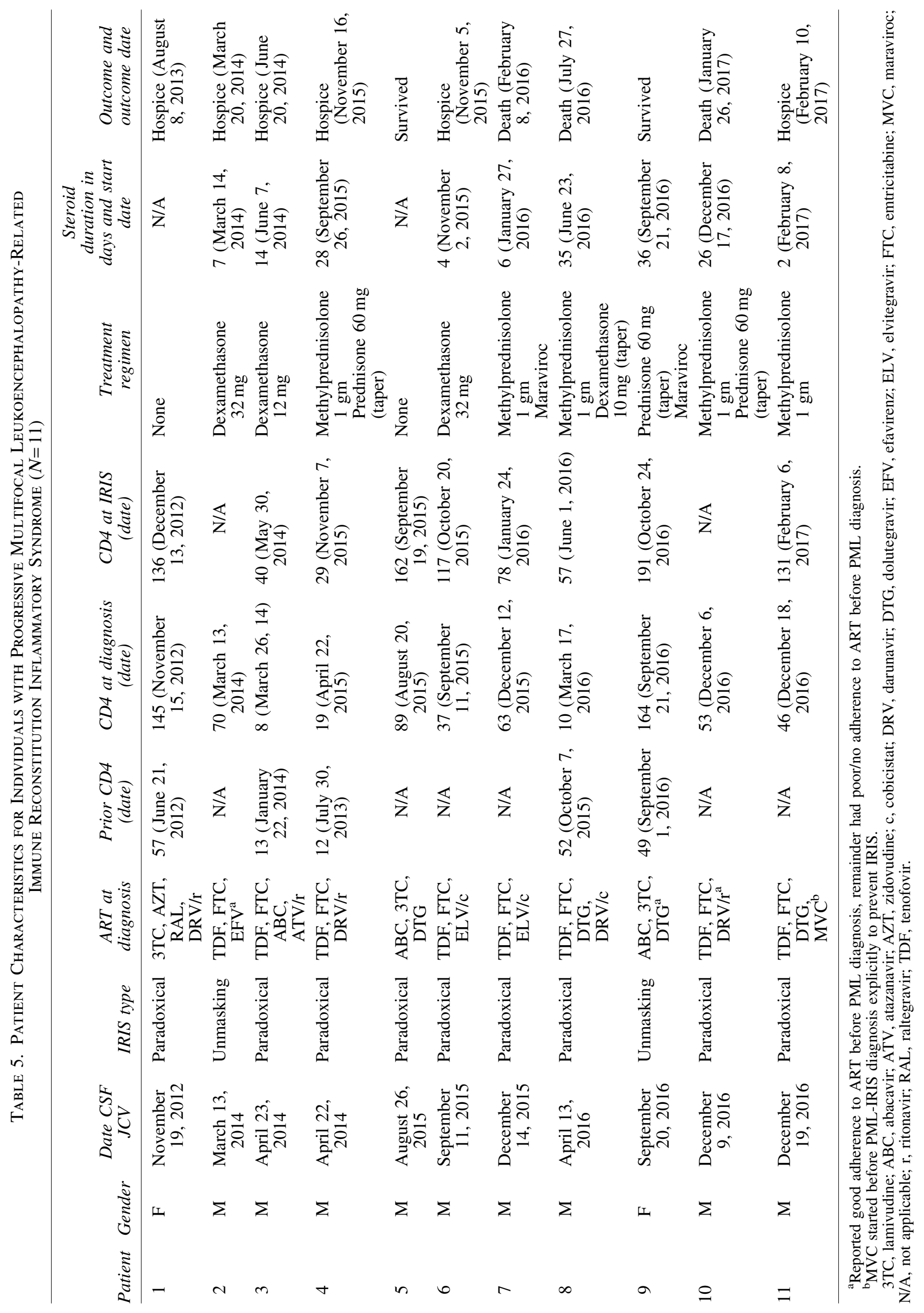




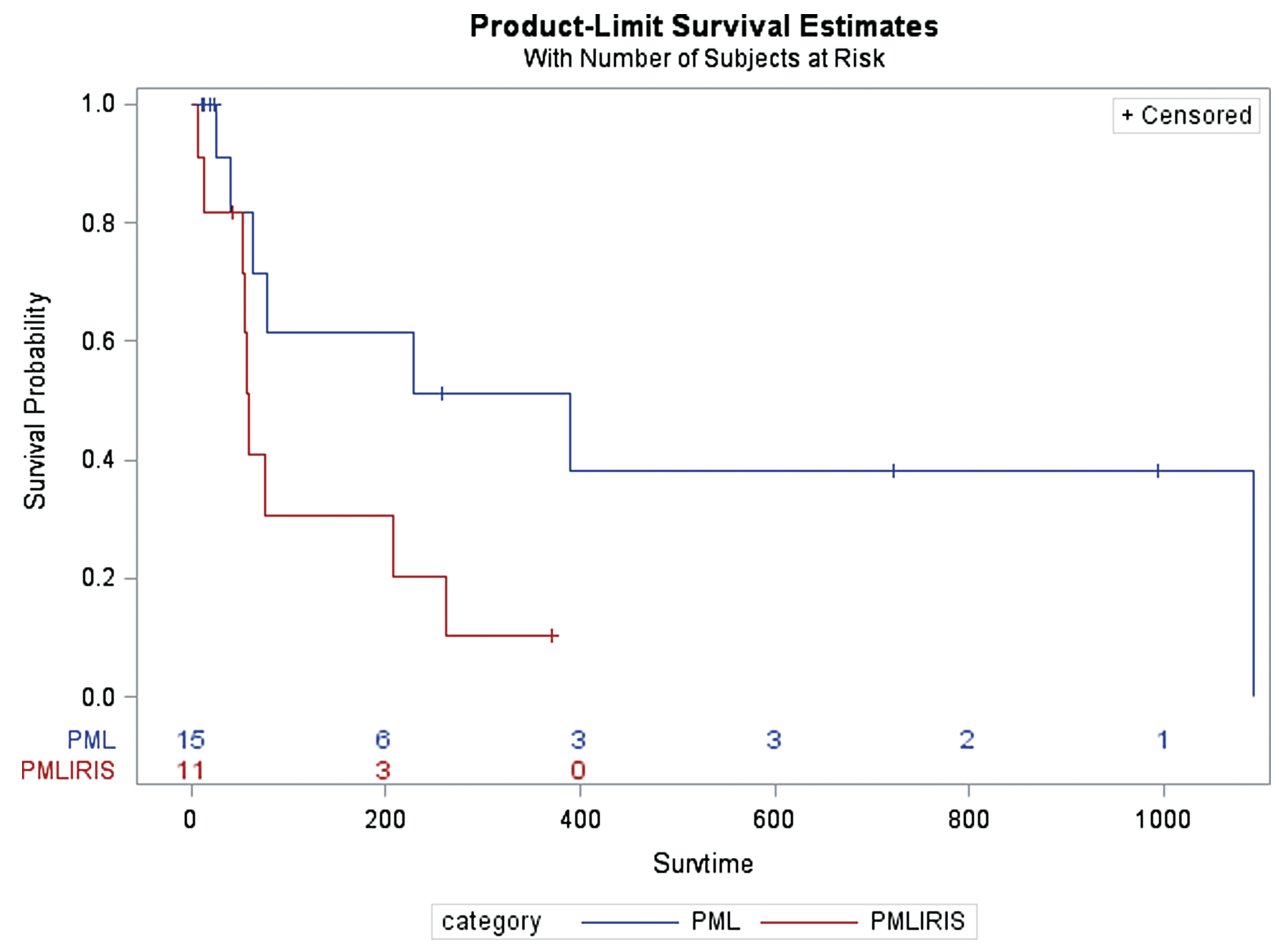

FIG. 2. Kaplan-Meier curve comparing survival of PML versus PML-IRIS patients. Log-Rank $p$ value: .05. Survtime, survival time. Color images are available online. potent regimens, may have affected the proportion of cases of PML-IRIS. $^{24}$

In addition to the high frequency of PML-IRIS, there was a surprising proportion of patients who were felt to have an asymptomatic positive CSF JCV PCR result (6 of 32, 18\%). The JCV PCR testing has been shown to have a very high specificity of over $90 \%$ and false-positive results are felt to be exceedingly rare. ${ }^{25,26}$ Of interest, two recent case series reviewing patients with detectable CSF JCV PCR found positive results in 11 of $25(44 \%)$ and 8 of $43(19 \%)$ of patients who ultimately received diagnoses other than PML or PMLIRIS. $^{27,28}$ In one series, other CNS OIs are described in 4 of $11(36 \%)$ of patients with cryptococcal meningitis (one case) and toxoplasmosis (three cases). ${ }^{28}$ Although JCV is known to reside dormant in the renal epithelium after primary infection, it is not yet known how or when JCV enters the CNS to infect oligodendrocytes. ${ }^{29,30}$ It is not clear if the asymptomatic positive CSF JCV PCR results in this work represent an asymptomatic infection that was detected before onset of symptoms or instead translocation from an asymptomatic viremia into the CSF in the setting of a weakened immune system or CNS inflammation from other processes. Our work supports these recent reviews by observing that 6 of $32(18 \%)$ of PLWH who had a positive CSF JCV PCR did not meet diagnostic criteria for PML or PML-IRIS, 3 of whom (50\%) had a coexisting OI. This consistent finding of a significant proportion of patients with asymptomatic positive CSF JCV PCR results supports the judicious use of diagnostic testing to prevent unnecessary ordering of expensive testing.

The present study also found surprisingly high mortality rates among this group of patients, with 16 of $26(62 \%)$ patients overall and 9 of $11(82 \%)$ patients with PML-IRIS progressing to death or hospice during the study period. This is considerably higher than several recently published case series and cohort studies, which found 1-year mortality rates to be improving to $25 \%-36 \%$ with the advent of modern ART as well as improved supportive care measures. ${ }^{31-33}$ One possible explanation is the fact that the current study assessed all-cause mortality rather than PML-specific mortality. This is due to the fact that a significant proportion of patients were discharged to hospice and did not have subsequent encounters within the EHR, creating difficulty in determining causespecific mortality. Whether the higher mortality rate is related to the higher incidence of PML-IRIS observed in this study or due to other factors, patients with both PML and PML-IRIS suffered poor outcomes.

This study also identified several factors associated with both the development of PML-IRIS as well as progression to death or discharge to hospice. Patients presenting with motor weakness $(\mathrm{OR}=8.75,95 \%$ CI: 0.88-86.60), dysarthria $(\mathrm{OR}=10.67,95 \% \mathrm{CI}: 1.71-66.72)$, and ataxia $(\mathrm{OR}=7.00$, 95\% CI: $1.20-40.83)$. Although not statistically significant, patients with PML-IRIS, dysarthria, visual changes, and CD4 cell counts of 50 cells/ $\mu \mathrm{L}$ or less trended toward higher odds of progression to death or discharge to hospice. A trend toward poorer outcomes with PML-IRIS is counter to what was seen in a recent similar study in Spain, where patients with PML-IRIS were noted to have improved survival when compared with patients with PML alone. ${ }^{18}$ It is not clear what is responsible for these disparate results, but one potential confounder is the large proportion of patients in this present study who were discharged to hospice, which was included in the composite outcome. Identifying patients who are at the highest risk for poor outcomes may help target individuals who could benefit most from new therapies.

Several studies have looked at potential therapies to treat or prevent the development of PML-IRIS. Maraviroc has garnered a growing interest in the prevention of development of PML-IRIS, as the migration of inflammatory cells to the CNS related to the development of PML-IRIS appears to occur in a CCR5-dependent fashion. ${ }^{9,34,35}$ Several small reports and case series have supported this conjecture. ${ }^{12,35-37}$ 
Although the CADIRIS study, a large randomized controlled trial evaluating the use of maraviroc for the prevention of development of any IRIS-related disease, ultimately found no reduction in incident IRIS with the addition of maraviroc, there are several potential limitations to applying this study to the PML population as there were no instances of PML identified in the CADIRIS study. ${ }^{13}$ Therefore, the findings of the CADIRIS study are not applicable to PML-IRIS. Although more widely used for the treatment of PML-IRIS, the data supporting the use of corticosteroids are largely based on observational and anecdotal data, with limited information on dosing recommendations. ${ }^{7,8}$ The corticosteroids used, as well as their dose and duration, are outlined in this study, and these were observed to vary greatly between patients. Although those who were treated with corticosteroids tended to have nonstatistically significant poorer outcomes, this may be in part related to selection bias. Corticosteroids were primarily used in patients with PML-IRIS, who were also observed to have more severe presentations and poorer outcomes, limiting the interpretation of these results. Other agents that have been considered for the treatment or prevention of PML or PML-IRIS include cidofovir, CMX001, and mefloquine, with mixed but generally unfavorable results. ${ }^{38-40}$ Although use of maraviroc or corticosteroids may indeed be ineffective, any potential benefit remains theoretical at this time. Identifying patients who would benefit most from interventions will help in the search for effective therapies for PML and PML-IRIS beyond ART.

Limitations of this work include the retrospective and observational nature of the study as well as the small number of patients included which limits statistical power. The results should therefore be viewed as hypothesis generating. It may be that use of medications to treat or prevent PML-IRIS, whether they be corticosteroids or maraviroc, are only beneficial in reducing mortality in the most ill subset of patients. A potential limitation of misclassification bias, incorrectly assigning a patient to PML or PML-IRIS, was accounted for by using strict definitions before the analysis of results.

PML and PML-IRIS continue to have devastating outcomes despite the advent of modern ART, with mortality rates above $50 \%$, as seen in this study and median survival of 266 days for patients with PML and 109 days for patients with PML-IRIS. Current evidence supporting use of various agents for the treatment or prevention of PML and PML-IRIS is lacking. Further studies are needed to assess preventive measures as well as therapeutic interventions for this devastating disease.

\section{Acknowledgments}

This work was supported by the National Center for Advancing Translational Sciences of the National Institutes of Health (grant nos. nL1 TR002378 and TL1 TR002382) to N.A.S. This work was also supported by the Center for AIDS Research at Emory University (grant no. P30AI050409). The authors would like to thank the Emory University CFAR Clinical Research Core, including Cameron England and Jeselyn Rhodes for their assistance with the data abstraction.

Data was presented at IDWeek 2018 meetings.

\section{Author Disclosure Statement}

No competing financial incentives exist.

\section{References}

1. Tan CS, Koralnik IJ. JC, BK, and other polyomaviruses: Progressive multifocal leukoencephalopathy (PML). In: Mandell, Douglas, and Bennett's Principles and Practice of Infectious Diseases, 8th ed (Bennett JE, Dolin R, Blaser MJ, eds.) Philadelphia, PA: Elsevier Saunders, 2015, pp. 1807-1814.

2. Padgett BL, Walker DL, ZuRhein GM, Eckroade RJ, Dessel BH: Cultivation of papova-like virus from human brain with progressive multifocal leucoencephalopathy. Lancet 1971;1:1257-1260.

3. Panel on Opportunistic Infections in HIV-Infected Adults and Adolescents: Guidelines for the prevention and treatment of opportunistic infections in HIV-infected adults and adolescents: Recommendations from the Centers for Disease Control and Prevention, the National Institutes of Health, and the HIV Medicine Association of the Infectious Diseases Society of America. Available at http://aidsinfo .nih.gov/contentfiles/lvguidelines/adult_oi.pdf Accessed February 25, 2019.

4. Salvana EM, Salata RA: Infectious complications associated with monoclonal antibodies and related small molecules. Clin Microbiol Rev 2009;22:274-290.

5. Fournier A, Martin-Blondel G, Lechapt-Zalcman E, et al.: Immune reconstitution inflammatory syndrome unmasking Intranasalor worsening AIDS-related progressive multifocal leukoencephalopathy: A literature review. Front Immunol 2017;8:577.

6. Antinori A, Cingolani A, Lorenzini P, et al.: Clinical epidemiology and survival of progressive multifocal leukoencephalopathy in the era of highly active antiretroviral therapy: Data from the Italian Registry Investigative Neuro AIDS (IRINA). J Neurovirol 2003;9(Suppl. 1):47-53.

7. Cinque P, Koralnik IJ, Gerevini S, Miro JM, Price RW: Progressive multifocal leukoencephalopathy in HIV-1 infection. Lancet Infect Dis 2009;9:625-636.

8. Tan K, Roda R, Ostrow L, McArthur J, Nath A: PML-IRIS in patients with HIV infection: Clinical manifestations and treatment with steroids. Neurology 2009;72:1458-1464.

9. Giacomini PS, Rozenberg A, Metz I, et al.: Maraviroc and JC virus-associated immune reconstitution inflammatory syndrome. N Engl J Med 2014;370:486-488.

10. Schwab N, Hohn KG, Schneider-Hohendorf T, et al.: Immunological and clinical consequences of treating a patient with natalizumab. Mult Scler 2012;18:335-344.

11. Metz I, Radue EW, Oterino A, et al:: Pathology of immune reconstitution inflammatory syndrome in multiple sclerosis with natalizumab-associated progressive multifocal leukoencephalopathy. Acta Neuropathol 2012;123:235-245.

12. Shahani L, Shah M, Tavakoli-Tabasi S: Immune reconstitution inflammatory syndrome in a patient with progressive multifocal leukoencephalopathy. BMJ Case Rep 2015; 2015:bcr2014207325.

13. Sierra-Madero JG, Ellenberg SS, Rassool MS, et al:: Effect of the CCR5 antagonist maraviroc on the occurrence of immune reconstitution inflammatory syndrome in HIV (CADIRIS): A double-blind, randomised, placebo-controlled trial. Lancet HIV 2014;1:e60-e67.

14. Steiner I, Benninger F: Maraviroc in PML-IRIS: A separate ball game under HIV infection and natalizumab? Neurol Neuroimmunol Neuroinflamm 2017;4:e331.

15. Berger JR, Aksamit AJ, Clifford DB, et al:: PML diagnostic criteria: Consensus statement from the AAN Neuroinfectious Disease Section. Neurology 2013;80:1430-1438. 
16. Engsig FN, Hansen $\mathrm{AB}$, Omland $\mathrm{LH}$, et al:: Incidence, clinical presentation, and outcome of progressive multifocal leukoencephalopathy in HIV-infected patients during the highly active antiretroviral therapy era: A nationwide cohort study. J Infect Dis 2009;199:77-83.

17. Falco V, Olmo M, del Saz SV, et al.: Influence of HAART on the clinical course of HIV-1-infected patients with progressive multifocal leukoencephalopathy: Results of an observational multicenter study. J Acquir Immune Defic Syndr 2008;49:26-31.

18. Sainz-de-la-Maza S, Casado JL, Perez-Elias MJ, et al.: Incidence and prognosis of immune reconstitution inflammatory syndrome in HIV-associated progressive multifocal leucoencephalopathy. Eur J Neurol 2016;23:919-925.

19. Psichogiou M, Basoulis D, Tsikala-Vafea M, Vlachos S, Kapelios CJ, Daikos GL: Integrase strand transfer inhibitors and the emergence of immune reconstitution inflammatory syndrome (IRIS). Curr HIV Res 2017;15:405-410.

20. Letendre SL, Mills AM, Tashima KT, et al.: ING116070: A study of the pharmacokinetics and antiviral activity of dolutegravir in cerebrospinal fluid in HIV-1-infected, antiretroviral therapy-naive subjects. Clin Infect Dis 2014;59: 1032-1037.

21. Cusini A, Vernazza PL, Yerly S, et al.: Higher CNS penetration-effectiveness of long-term combination antiretroviral therapy is associated with better HIV-1 viral suppression in cerebrospinal fluid. J Acquir Immune Defic Syndr 2013;62:28-35.

22. Caniglia EC, Cain LE, Justice A, et al.: Antiretroviral penetration into the CNS and incidence of AIDS-defining neurologic conditions. Neurology 2014;83:134-141.

23. Chang CC, Kangethe R, Omarjee S, et al.: Relationship of human immunodeficiency virus viral load in cerebrospinal fluid and plasma in patients co-infected with Cryptococcal meningitis. Open Forum Infect Dis 2017;4:ofx032.

24. Manabe YC, Campbell JD, Sydnor E, Moore RD: Immune reconstitution inflammatory syndrome: Risk factors and treatment implications. J Acquir Immune Defic Syndr 2007;46:456-462.

25. de Luca A, Cingolani A, Linzalone A, et al.: Improved detection of JC virus DNA in cerebrospinal fluid for diagnosis of AIDS-related progressive multifocal leukoencephalopathy. J Clin Microbiol 1996;34:1343-1346.

26. Marzocchetti A, Di Giambenedetto S, Cingolani A, Ammassari A, Cauda R, De Luca A: Reduced rate of diagnostic positive detection of JC virus DNA in cerebrospinal fluid in cases of suspected progressive multifocal leukoencephalopathy in the era of potent antiretroviral therapy. J Clin Microbiol 2005;43:4175-4177.

27. Wang Y, Kirby JE, Qian Q: Effective use of JC virus PCR for diagnosis of progressive multifocal leukoencephalopathy. J Med Microbiol 2009;58:253-255.

28. Mornese Pinna S, Scarvaglieri E, Milia MG, et al:: Detectable cerebrospinal fluid JCV DNA in late-presenting HIV-positive patients: Beyond progressive multifocal leukoencephalopathy? J Neurovirol 2017;23:763-767.

29. Assetta B, Atwood WJ: The biology of JC polyomavirus. Biol Chem 2017;398:839-855.
30. Knowles WA: Discovery and epidemiology of the human polyomaviruses $\mathrm{BK}$ virus $(\mathrm{BKV})$ and $\mathrm{JC}$ virus $(\mathrm{JCV})$. Adv Exp Med Biol 2006;577:19-45.

31. Casado JL, Corral I, Garcia J, et al:: Continued declining incidence and improved survival of progressive multifocal leukoencephalopathy in HIV/AIDS patients in the current era. Eur J Clin Microbiol Infect Dis 2014;33:179-187.

32. Piza F, Fink MC, Nogueira GS, Pannuti CS, Oliveira AC, Vidal JE: JC virus-associated central nervous system diseases in HIV-infected patients in Brazil: Clinical presentations, associated factors with mortality and outcome. Braz J Infect Dis 2012;16:153-156.

33. Yamamoto K, Watanabe K, Kikuchi Y, Oka S, Gatanaga H: Long-term functional prognosis of patients with HIVassociated progressive multifocal leukoencephalopathy in the era of combination ART. AIDS Patient Care STDs 2015;29:1-3.

34. Martin-Blondel G, Brassat D, Bauer J, Lassmann H, Liblau RS: CCR5 blockade for neuroinflammatory diseasesbeyond control of HIV. Nat Rev Neurol 2016;12:95-105.

35. Stork L, Bruck W, Bar-Or A, Metz I: High CCR5 expression in natalizumab-associated progressive multifocal leukoencephalopathy immune reconstitution inflammatory syndrome supports treatment with the CCR5 inhibitor maraviroc. Acta Neuropathol 2015;129:467-468.

36. Martin-Blondel G, Cuzin L, Delobel P, et al.: Is maraviroc beneficial in paradoxical progressive multifocal leukoencephalopathy-immune reconstitution inflammatory syndrome management? AIDS (London, England) 2009;23: 2545-2546.

37. Middel A, Arends JE, van Lelyveld SF, et al.: Clinical and immunologic effects of maraviroc in progressive multifocal leukoencephalopathy. Neurology 2015;85:104-106.

38. Clifford DB, Nath A, Cinque P, et al:: A study of mefloquine treatment for progressive multifocal leukoencephalopathy: Results and exploration of predictors of PML outcomes. J Neurovirol 2013;19:351-358.

39. De Luca A, Ammassari A, Pezzotti P, et al:: Cidofovir in addition to antiretroviral treatment is not effective for AIDS-associated progressive multifocal leukoencephalopathy: A multicohort analysis. AIDS (London, England) 2008;22:1759-1767.

40. Gosert R, Rinaldo CH, Wernli M, Major EO, Hirsch HH: CMX001 (1-O-hexadecyloxypropyl-cidofovir) inhibits polyomavirus JC replication in human brain progenitorderived astrocytes. Antimicrob Agents Chemother 2011;55: 2129-2136.

Address correspondence to: Nathan A. Summers, MD Division of Infectious Diseases Department of Medicine Emory University 1518 Clifton Road CNR 7000Q Atlanta, GA 30322

E-mail: nasumme@emory.edu 